OPEN ACCESS

Edited by:

Mohiuddin Md. Taimur Khan, Washington State University Tri-Cities,

United States

Reviewed by:

Behzad Heibati,

University of Oulu, Finland Keith Dana Thomsen,

United States Department of Energy

(DOE), United States

${ }^{*}$ Correspondence:

Shengfeng Wang

shengfeng1984@126.com

Specialty section:

This article was submitted to Environmental health and Exposome,

a section of the journal

Frontiers in Public Health

Received: 25 March 2021

Accepted: 01 July 2021

Published: 04 August 2021

Citation:

Liu T, Chen R, Zheng R, Li L and Wang $S$ (2021) Household Air

Pollution From Solid Cooking Fuel

Combustion and Female Breast

Cancer.

Front. Public Health 9:677851.

doi: 10.3389/fpubh.2021.677851

\section{Household Air Pollution From Solid Cooking Fuel Combustion and Female Breast Cancer}

\author{
Tanxin Liu ${ }^{1}$, Ru Chen ${ }^{2}$, Rongshou Zheng ${ }^{2}$, Liming $\mathrm{Li}^{1}$ and Shengfeng Wang ${ }^{1 *}$ \\ ${ }^{1}$ Department of Epidemiology and Biostatistics, School of Public Health, Peking University Health Science Center, Beijing, \\ China, ${ }^{2}$ National Cancer Center/National Clinical Research Center for Cancer/Cancer Hospital, Chinese Academy of Medical \\ Sciences and Peking Union Medical College, Beijing, China
}

Background: Women bear a large share of disease burden caused by household air pollution due to their great involvement in domestic activities. Pollutant emissions are believed to vary by exposure patterns such as cooking and space heating. Little is known about the independent effect of solid cooking fuel combustion on breast cancer risk. We aimed to examine the association of indoor coal and wood combustion for cooking with breast cancer risk.

Methods: During June 2004-July 2008, participants aged 30-79 from 10 diverse regions across China were enrolled in the China Kadoorie Biobank. Primary cooking fuel use information in up to three residences was self-reported at baseline. Multivariable logistic regression models yielded adjusted odds ratios (ORs) and 95\% confidence intervals (Cls).

Results: A total of 290,396 female participants aged 30-79 were included in the main analysis. Compared with long-term clean fuel users, the fully adjusted ORs were 2.07 (95\% Cl: 1.37-3.13) for long-term coal users, 1.12 (95\% Cl: 0.72-1.76) for long-term wood users, and 0.98 (95\% Cl: 0.55-1.74) for those who used mixed solid fuels to cook. Those who had switched from solid to clean fuels did not have an excess risk of breast cancer (OR: 0.88, 95\% Cl 0.71-1.10).

Conclusion: Long-term solid fuel combustion for cooking may increase the risk of breast cancer. The strength of association is stronger among coal users than wood users. Targeted interventions are needed to accelerate the access to clean and affordable energy.

Keywords: household air pollution, breast cancer, cooking fuel, indoor air pollution, solid fuel

\section{INTRODUCTION}

Household air pollution (HAP) causes immense disease burden throughout the world. Around 3.8 million people died prematurely from illness attributed to HAP (1). Globally, "by far the most important direct health risk is the pollution caused by incomplete combustion of solid fuels for cooking, heating and lighting" (2). The adverse impacts from HAP are largely caused by energy poverty, especially in rural regions of the low-and middle-income countries (LMICs) where some residents lack access to affordable, clean energy such as electricity, biogas and gas (3). 
Instead, they rely on solid fuel collected from agricultural residues, hauled from kilometers away, or purchased at a low price to meet daily energy demand (3). According to the World Health Organization (3), solid fuel includes coal as well as biomass fuels (referring to renewable plant-based material such as wood, crop wastes and charcoal), providing heat and light during the process of combustion (4). Incomplete combustion of solid fuels produces high levels of HAP with a range of harmful pollutants, including particulate matter, sulfur oxides, nitrogen oxides, carbon monoxide, polycyclic aromatic hydrocarbons, formaldehyde, and dioxins, to name a few (5-9). In contrast, clean fuel mainly includes "electricity, liquefied petroleum gas (LPG), piped natural gas (PNG), biogas, solar and alcohol fuels", which produces low levels of emissions of particulate matter, sulfur dioxide and other by-products of incomplete combustion when properly used (9). Although the past few years have witnessed a surge in technological innovation in the household energy sector, progress remains too slow to displace the polluting fuel combustion systems and thereby mitigate their health impacts. Based on the most recent global estimates, more than 2.7 billion people heavily relied on domestic solid fuels in 2015, including 450 million people in China (10).

Household air pollution from solid cooking fuel (notably coal and wood) has been categorized as a Group 2A carcinogen (11). Special attention should be placed to females who spend considerable amount of time in proximity to polluting sources due to their great involvement in daily cooking activity (4). Ambient air pollutants (e.g., particulate matter, polycyclic aromatic hydrocarbons) may cause tumor formation in breast and cervix uteri (12-14). Evidence for the relationship with household air pollutants remains scarce. Three previous studies have examined the indoor solid fuel combustion as a risk factor for breast cancer and yielded inconsistent result (1517). Previous studies on this topic have mainly conducted in high-income countries and focused on wood burning $(15,16)$. However, in some coal-producing countries such as China and India, coal is considered as a domestic source of energy (11). There is a paucity of studies on the potential impact from indoor coal combustion for cooking. Furthermore, HAP from cooking and space heating are two different exposure patterns, which may have different influences on carcinogenesis. A stove might be kept going all day for heating in winter months (3). By contrast, cooking produces HAP several times per day with a shorter period $(3,18)$. Field measurement reported significantly lower emissions of pollutants from domestic solid fuel combustion during heating compared to those from cooking (19). Epidemiological evidence on HAP exposure from cooking and heating reported different associations with lung cancer (20). One previous CKB study on HAP from heating fuel use and breast cancer mortality did not find any evident relationship with breast cancer mortality (17). Little is known about the independent effect of cooking fuel use on female breast cancer

Abbreviations: HAP, household air pollution; PAHs, Polycyclic aromatic hydrocarbons; 95\%CI, confidence interval; HRs, hazard ratios; IQR, interquartile range; $\mathrm{SD}$, standard deviation. risk. This study reported findings on the solid cooking fuel combustion with breast cancer risk among 290,396 females.

\section{METHODS}

\section{Study Population}

We used the baseline data from China Kadoorie Biobank (CKB) (21). It was initially set up to recruit 500,000 permanent residents aged 35-74 years without a known disability in five rural and five urban regions (100,000 for each region) (Supplementary Figure 1). From June 2004 to July 2008, $512,891$ participants aged $30-79$ years (302,510 females, $59.0 \%)$ completed the baseline survey. To encourage participation, we included 10,715 participants whose age was slightly outside the target range, resulting in the baseline age range $30-79$ years. In $2008, \sim 4 \%$ of participants were randomly selected to attend the resurvey with repeated interviews. Details of this biobank have been described elsewhere $(21,22)$.

Registered participants went to the local assessment stations after signing the informed consent. Trained health staffs conducted a computer-assisted interview with participants to collect a set of information, including demographics, lifestyle behaviors, and medical history via a standard electronic questionnaire. All participants also underwent physical measurements and a $10 \mathrm{ml}$ blood sample collection. Ethical approval of $\mathrm{CKB}$ was obtained from the Ethical Review Committee of the Chinese Center for Disease Control and Prevention and the Oxford Tropical Research Ethics Committee.

\section{Assessment of Exposure and Outcome}

Participants were asked to recall their cooking frequency, type of cooking fuels and ownership of ventilated stoves for up to three most recent residences (each lived at least 1 year), and duration (in years) in each residence. Participants were asked, "In your present \& two previous houses, how often did you cook at home?" Participants chose from the options of daily, weekly, monthly, rarely/never, no cooking facility (23). For those who cooked at least monthly, we further asked their primary cooking fuel which they used most frequently at each residence (coal, wood, gas, electricity, other unspecified). Solid fuels included coal and wood, whereas clean fuels included gas and electricity. Participants who reported having cooking facilities were asked the presence of chimney or extractor related to cooking stove(s) used (23). Participants cooking daily or weekly were considered as cooking regularly (23-25). Long-term exposure pattern was examined by classifying participants who cooked regularly into three groups: those who always used the same fuel in all residences (always solid, always clean), and those who used solid fuels in previous residence(s) and then used clean fuels in the present residence. Participants who always used solid fuels were further divided into three groups (always wood, always coal, a mixture of coal and wood). All participants were asked if a doctor told them that they had had cancers and the site of cancers. If participants suffered from more than one cancer, the one that occurred first was recorded. The cancer status was also confirmed by the hospital admission in the resurvey. We considered breast cancer (ICD-10: C50.42) as our primary outcome. 


\section{Covariates}

Covariates of potential interest comprised of demographic characteristics, lifestyle factors, household air pollution, reproductive history and family history, which were selected based on previous literature on this topic $(15,16,26)$. The demographic variables included age (continuous variable), study region (urban, rural), education (no education, primary school, middle school, high school and above), occupation (unemployed/retired, agricultural worker, factory worker, non-manual worker), annual family income $(<10,000$, 10,000-34,999, $\geq 35,000$ yuan), marital status (married, never married/widowed/separated/divorced). Lifestyle and HAP variables included current smoking status (not smoke/occasionally, daily/on most days), alcohol drinking (never/rarely, occasionally/at certain season, monthly/weekly), body mass index (BMI) (continuous variable), environmental tobacco smoke exposure (ETS) (never/occasionally, 1-5 days a week, daily) and ownership of stove ventilation (all stoves, not all, none). Reproductive history included age at menopause (premenopausal, menopause age $<50$, menopause age $\geq 50$ ), parity $(0,1,2, \geq 3)$, use of oral contraceptive pills (never, ever). We included physical activity levels (metabolic equivalent of task, hours/day), family history of cancer (presence or absence) and consumption of preserved vegetables (daily/4-6 days per week, 1-3 days per week, monthly, never/rarely) in our sensitivity analysis.

\section{Statistical Analyses}

We restricted our analyses to females $(n=302,510)$ and excluded 2,238 participants who did not report cooking information at three residences or used other unspecified fuels, leaving 300,272 for baseline characteristics estimation. We further excluded participants who did not cook regularly at three residences $(n=$ $8,839,2.9 \%$ ) and those with fluctuating exposure condition (using clean fuel at the first residence, solid fuel at the second residence and clean fuel again at the third residence) ( $n=1,037,0.03 \%)$. Finally, a total of 290,396 participants were included in the main analyses.

Adjusted values of baseline characteristics by cooking fuel category were presented, with adjustment for age and region where appropriate. We adopted multivariable logistic regressions to estimate odds ratios (ORs) of breast cancer. Model 1 was adjusted for age and study region (18). Model 2 adjustment included all demographic variables (age, study region, education, occupation, annual family income, marital status) and lifestyle variables (smoking, alcohol consumption, BMI, ETS, and ownership of stove ventilation) (15). Model 3 adjustment included all above variables and reproductive history (age at menopause, parity, contraceptive use) (15). We considered clean fuel group as our reference (defined as using gas and/or electricity in all recalled residences) $(18,23,25)$. We also calculated the duration of solid fuel exposure during the recall period by summing the number of years at three residences where solid fuel (coal or wood) was reported as the primary cooking fuel. Duration of exposure was classified into three groups: never, duration $<25$, duration $\geq 25$. Linear trend was tested by modeling a continuous variable that was assigned the median year of duration for each participants' exposure category (27). Considering the biology of female breast cancer and HAP, we stratified the analysis by environmental tobacco smoke exposure, menopause status and contraceptive use, controlling for the same set of covariates as appropriate. The tests for interaction were performed using likelihood ratio test comparing models with and without the cross-product term.

Several sensitivity analyses were further performed. First, we additionally adjusted for potential covariates, including physical activity, family history of cancer and consumption of preserved vegetables. Second, we excluded participants who smoked daily/on most days; those who were exposed to environmental tobacco smoke daily or almost every day; those who were nulliparous; those who had ever used oral contraceptive pills. Third, we selected the lag period of 5 years and 10 years, discounting the exposure during this period. Finally, we explored the association of HAP from solid cooking fuel use with breast cancer mortality, using time in study as the time scale. All analyses were performed using Stata software 15.1 (StataCorp, TX, USA).

\section{RESULTS}

Of the 300,272 females [mean (SD) age 51.46 (10.48) years], 51.1 $\%$ always used solid cooking fuel and $18.0 \%$ always used clean fuel in all residences. Females who always used solid fuels tended to be older, more likely to live in rural region, less educated, more exposed to passive smoking, less likely to use oral contraceptive pills and had lower household income in comparison with clean fuel users (Table 1).

We documented 551 participants diagnosed with breast cancer. Compared with long-term clean cooking fuel use, longterm coal combustion was associated with a higher risk of breast cancer (fully adjusted OR:2.07, 95\%CI: 1.37-3.13) (Table 2). Fully adjusted ORs of breast cancer were 1.12 (95\%CI: 0.72-1.76) for those who always used wood, and 0.98 (95\% CI: 0.55-1.74) for those who used mixed solid fuels to cook [mean duration of exposure: 16 years]. Long-term solid cooking fuel combustion [mean duration of exposure: 30 years] appeared to confer a higher risk of breast cancer, albeit not significant (fully adjusted OR,1.19 (95\%CI: 0.84-1.67). There was no elevated cancer risk among women who had switched into clean fuels [mean duration of exposure: 18 years]. No evident relationship was observed between solid fuel use and breast cancer risk.

There was no statistical effect measure modification by environmental tobacco smoking (ETS), cooking stove ventilation, menopausal status or contraceptive use (Figure 1). The strength of observed associations remained largely unchanged after excluding the mixed fuel users. The adjusted OR was somewhat stronger in females with daily ETS exposure (OR: 3.26, 95\% CI: 1.83-5.81) than in those who got exposed to ETS 1-5 days per week (OR 0.98, 95\% CI: $0.38-2.48$ ) and in those who never/occasionally got exposed to ETS (OR 0.73, 95\%CI: 0.38-1.38).

In the sensitivity analyses, the association of solid fuel exposure and breast cancer risk was unaltered after adjusting 
TABLE 1 | Baseline characteristics by cooking fuel use $\left(n=300,272^{\mathrm{a}}\right)$.

\begin{tabular}{|c|c|c|c|c|}
\hline \multirow[b]{2}{*}{ Characteristics } & \multicolumn{4}{|c|}{ Cooking fuel exposure } \\
\hline & Solid fuel & Clean fuel & Solid to clean fuel ${ }^{b}$ & No cooking \\
\hline No. of participants, $n$ (\%) & $152802(51.1)$ & $53875(18.0)$ & 83719 (27.9) & 8839 (3.0) \\
\hline Age at baseline (y) & 53.0 & 46.2 & 52.8 & 45.5 \\
\hline BMl $\left(\mathrm{kg} / \mathrm{m}^{2}\right)$ & 23.5 & 24.0 & 24.3 & 24.4 \\
\hline Physical activity (MET-h/d) & 20.3 & 19.4 & 21.0 & 23.4 \\
\hline Rural (\%) & 91.4 & 10.2 & 20.8 & 46.5 \\
\hline Married (\%) & 89.3 & 87.1 & 89.4 & 88.7 \\
\hline Primary school and lower (\%) & 6.8 & 3.6 & 5.6 & 5.5 \\
\hline Income <10,000 (Yuan/y) (\%) & 41.0 & 11.7 & 18.8 & 8.4 \\
\hline No occupation (\%) & 22.6 & 39.7 & 40.6 & 21.2 \\
\hline Tobacco smoking $^{d}(\%)$ & 3.9 & 4.5 & 4.6 & 4.5 \\
\hline Alcohol drinking ${ }^{e}(\%)$ & 1.7 & 2.9 & 1.9 & 3.1 \\
\hline Family history of cancer (\%) & 16.2 & 16.9 & 17.8 & 16.1 \\
\hline Passive smoking ${ }^{\dagger}(\%)$ & 87.1 & 74.9 & 83.9 & 75.3 \\
\hline Good ventilationg (\%) & 11.7 & 27.2 & 8.2 & 15.5 \\
\hline Postmenopause ${ }^{h}(\%)$ & 82.9 & 78.8 & 82.6 & 78.5 \\
\hline Having live birth (\%) & 98.8 & 98.5 & 99.1 & 97.1 \\
\hline Contraceptive use ${ }^{\text {h }}(\%)$ & 5.5 & 12.6 & 16.6 & 20.6 \\
\hline
\end{tabular}

We used linear models (for continuous variables) or logistic models (for categorical variables) to estimate predicted probabilities adjusted for age and region as appropriate. BMI, body mass index; MET-h/d, metabolic equivalent task-hours per day.

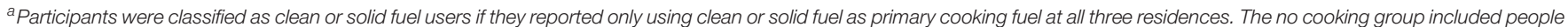

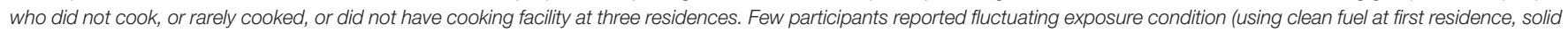
fuel at second residence, and then clean fuel again at the third residence) ( $n=1,037,0.3 \%)$, thus this group were not presented.

b "Solid to clean fuel" exposure was defined as using solid fuel (coal, wood) as the primary cooking fuel at previous residences and then used clean fuel at the current residence.

${ }^{c} 10,000$ Yuan $=1412.6688$ US dollar.

${ }^{d}$ Tobacco smoking was defined as smoking tobacco daily or on most days.

${ }^{e}$ Alcohol drinking was defined as drinking any alcohol usually at least once a week.

${ }^{f}$ Passive smoking was defined as ever lived with smoker in the same house for at least 6 months.

gGood ventilation was defined as all stoves for cooking with a chimney or extractor, or had no stoves at three residences.

${ }^{h}$ Variables had forty-three missing values.

for potential confounders and excluding regular smokers, nulliparous women and those who had ever used oral contraceptive drugs (Supplementary Table 1). When 5-year or 10-year lag period was adopted, the strength of observed associations of two cancers appeared to be increased among long-term wood users and overall long-term solid fuel users, yielding significant results (Supplementary Tables 2,3). We did not observe excess risk of breast cancer mortality, probably due to insufficient number of deaths (Supplementary Table 4).

\section{DISCUSSION}

In this study, we observed inconsistent associations of solid cooking fuel exposure with breast cancer risk. The adjusted ORs of breast cancer were not statistically significant among persistent solid fuel users in general (OR: 1.19, 0.84-1.67). In line with our finding, a case-control study of women on Long Island demonstrated no increased risk of breast cancer incidence in females who frequently burned wood in their home (16). However, when stratifying by type of solid fuel use, we observed a higher risk of breast cancer in persistent coal users (OR 2.07, 2.37-3.13) but not in persistent wood users. Apart from that, a prospective cohort study in the United States or Puerto Rico suggested that having indoor wood-burning stove/fireplace appeared to confer higher breast cancer risk $(\mathrm{HR}=1.11$, 95\%CI: 1.01-1.22) (15). Reports are inconsistent on which type of wood (synthetic or wood logs) can produce more polycyclic aromatic hydrocarbon (PAH) during domestic combustion $(5,6,28)$. Previous association studies and risk assessment mainly focused on household wood combustion. The present study examined both wood and coal exposure and yielded inconsistent associations with breast cancer. Further prospective evidence is needed to elucidate the relationship of individual and combined effect of wood and coal exposure with breast cancer risk. Moreover, previous CKB study on heating fuel use did not observe excess risk of breast cancer mortality in any solid fuel groups (10). In contrast, this study focused on cooking fuel use and firstly suggested a positive association of long-term coal combustion for cooking with breast cancer risk. The strength of association remained largely unchanged in sensitivity analyses (Supplementary Tables 1-3). A possible explanation is that solid fuel combustion for cooking has a longer lifetime duration and thus provides higher cumulative inhaled pollutants compared to solid fuel combustion for heating (18). HAP from heating is a seasonal exposure during winter months while HAP from cooking is a regular exposure in this study since we included 
TABLE 2 | Association of cooking fuel use with breast cancer risk among 290,396 participants ${ }^{a}$.

\begin{tabular}{|c|c|c|c|c|c|}
\hline & No. of participants at baseline, $n$ & Cases, $n$ & Model 1 & Model 2 & Model 3 \\
\hline \multicolumn{6}{|l|}{ Pattern of fuel use } \\
\hline Always clean fuel (reference) & 53875 & 148 & ref & ref & ref \\
\hline Solid to clean fuel & 83719 & 243 & $0.92(0.74-1.14)$ & $0.98(0.79-1.22)$ & $0.88(0.71-1.10)$ \\
\hline Always solid fuel & 152802 & 160 & $0.80(0.59-1.07)$ & $1.19(0.86-1.66)$ & $1.19(0.84-1.67)$ \\
\hline \multicolumn{6}{|l|}{ Solid cooking fuel type ${ }^{b}$} \\
\hline Always coal & 56835 & 83 & $1.48(1.01-2.17)$ & $1.81(1.22-2.67)$ & $2.07(1.37-3.13)$ \\
\hline Always wood & 65956 & 56 & $0.60(0.42-0.87)$ & $1.12(0.72-1.74)$ & $1.12(0.72-1.76)$ \\
\hline A mixture of coal and wood & 30011 & 21 & $0.69(0.40-1.19)$ & $0.94(0.53-1.65)$ & $0.98(0.55-1.74)$ \\
\hline \multicolumn{6}{|c|}{ Duration of solid fuel exposure $(y)^{c}$} \\
\hline Neverd & 53875 & 148 & ref & ref & ref \\
\hline Duration $<25$ & 115971 & 252 & $1.01(0.82-1.25)$ & $1.07(0.87-1.33)$ & $1.02(0.82-1.27)$ \\
\hline Duration $\geq 25$ & 120550 & 151 & $0.65(0.50-0.85)$ & $0.82(0.63-1.08)$ & $0.78(0.59-1.03)$ \\
\hline$P$ for trend & & & 0.0013 & 0.1561 & 0.0849 \\
\hline
\end{tabular}

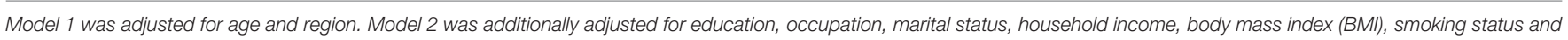
alcohol consumption, environmental tobacco smoke and stoves with ventilation. Model 3 was further adjusted for age at menopause, parity and use of oral contraceptive pills.

OR, odds ratio; $\mathrm{Cl}$, confidence interval.

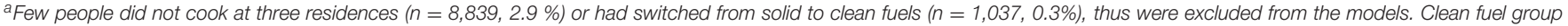
was considered as common reference group.

bSolid fuel group did not include those who had switched from solid to clean fuels ( $n=83,719)$.

${ }^{c}$ Duration was calculated by summing the number of years in each residence where solid fuel (coal, wood) were reported as the primary cooking fuel.

${ }^{d}$ The never group included those who used clean fuel at three residences.

\begin{tabular}{|c|c|c|c|c|}
\hline Subgroup & $\begin{array}{l}\text { No. of events } \\
\text { (clean/solid) }\end{array}$ & ORs $(95 \% \mathrm{CI})$ & ORs $(95 \% \mathrm{CI})$ & $\begin{array}{c}P \text { for } \\
\text { heterogeneity }\end{array}$ \\
\hline \multicolumn{5}{|c|}{ Environmental tobacco smoke } \\
\hline Never/occasionally & $83 / 49$ & & $0.73(0.38-1.38)$ & 0.60 \\
\hline $1-5$ days a week & $24 / 32$ & & $0.98(0.38-2.48)$ & \\
\hline Daily & $41 / 79$ & & $3.26(1.83-5.81)$ & \\
\hline \multicolumn{2}{|c|}{ Cooking stove ventilation } & & & 0.24 \\
\hline No & $3 / 56$ & $\mapsto$ & $0.92(0.22-3.77)$ & \\
\hline Yes & $145 / 104$ & & $1.47(0.98-2.21)$ & \\
\hline \multicolumn{2}{|l|}{ Menopause status } & & & 0.10 \\
\hline Premenopausal & $40 / 38$ & $=$ & $1.63(0.72-3.68)$ & \\
\hline Postmenopausal & $108 / 122$ & & $1.47(0.95-2.26)$ & \\
\hline \multicolumn{2}{|l|}{ Contraceptive use } & & & 0.61 \\
\hline Never & $129 / 147$ & & $1.47(0.97-2.23)$ & \\
\hline \multirow[t]{2}{*}{ Ever/current } & $19 / 13$ & 1 & $0.83(0.31-2.16)$ & \\
\hline & & 00 & & \\
\hline
\end{tabular}

FIGURE 1 | Adjusted ORs of breast cancer associated with long-term solid fuel use. Participants who had switched from solid to clean fuels or used a mixture of coal and wood were excluded. OR, odds ratio. Cl, confidence interval.

long-term solid fuel users who cooked daily or weekly in each residence lived at least 1 year. Differences in study design and covariates adjustment may also lead to different findings in two CKB studies. The association of HAP from different domestic activities (e.g., cooking and heating) with breast cancer risk needs future research to elucidate.

We observed no elevated breast cancer risk among women who had ceased using solid fuels. The point estimate of risk was lower in those who had switched from solid to clean fuels than long-term solid fuel users [OR]. Those who had ceased using solid fuels may get less exposed to solid fuel burning than longterm solid fuel users [duration in years: median (IQR): 16 (9-25) vs. 30 (21-41)]. Previous CKB study has demonstrated that the excess risk of all-cause mortality decreased by more than $60 \%$ in 5 years after cessation of indoor solid fuel burning (29). The present study further reported the health impact of cession from solid fuels on breast cancer risk. On the global basis, females bear a large share of disease burden caused by HAP due to their domestic roles (3). Our findings may have unique implications on females and suggest the reduction of solid fuel use for cooking. Targeted efforts are needed to accelerate the promotion of clean fuel production facilities and distribution networks.

The association between household air pollution and breast cancer is biologically plausible. Incomplete combustion of solid 
fuels releases many pollutants to the indoor and outdoor air, such as carbon monoxide, particulate matter, carcinogenic polycyclic aromatic hydrocarbons (PAHs) (5-9). Of all these pollutants, PAHs have been widely investigated and classified as carcinogenic to humans (IARC Group1) (30). About $60.5 \%$ of the global total $\mathrm{PAH}$ emissions were from combustion of biomass fuels including wood and crop residues (31). In China, coal and biomass fuel combustion are two major emission activates of PAHs, accounting for roughly 20 and 60\%, respectively (32). The field measurements showed that the total emission factors (EFs) of 28 PAHs from solid fuel combustion during a regular cooking period ranged from 20.7 to $535 \mathrm{mg} / \mathrm{kg}$ (33). EFs of PAHs varied from several $\mathrm{mg} / \mathrm{kg}$ for wood fuels to about $200 \mathrm{mg} / \mathrm{kg}$ for bituminous coal, a dirty fuel burned in domestic stoves in rural China due to low cost (34). Different emission profiles between coal and biomass combustion were also observed for predominant individual PAHs including benzo[a]pyrene $(\mathrm{BaP})$, pyrene (PYR), perylene (PER), Benzo[e]pyrene(BeP) and dibenzo[a,l]pyrene (DBalP) (33). Experimental evidence has confirmed that PAH metabolites can react with DNA and form PAH-DNA adducts, which leads to mutations of cancer related-genes and cell death (35-37). Potential carcinogenic pathways include sister chromatid exchange, mutations in TP53 as well as DNA methylation $(26,38,39)$. BaP, a marker of carcinogenic potency of $\mathrm{PAH}$ mixture and an endocrine-disrupting pollutant, was associated with increased risk of breast cancer in a French cohort $(13,40)$.

Persistent coal users had a higher risk of breast cancer than persistent wood users. We cannot directly compare our estimate for coal exposure with prior studies. To our knowledge, this is the first study which reports the association of breast cancer with coal combustion for cooking. Our results should be interpreted with caution due to relatively small number of cases. Given the sample sizes in the subgroups, we have sufficient power for coal combustion analysis (approximately 100\%) but not for wood combustion $(<50 \%)$. Although the play of chance cannot be ruled out, our analysis may suggest that pollutants from coal combustion could have more hazardous effect on breast cancer development than those from wood combustion. Different fuel properties and environmental condition contributes to the different formation and changes of trace organics emitted from combustion which may have adverse effects on breast carcinogenesis (41). Results from a previous field emission test study revealed that there was a statistically positive relationship between PAH derivatives and corresponding parent PAHs in emissions from coal combustion, but insignificant relationships for those from wood burning (41). PAHs exposure could be ubiquitous and concurrent multiple indoor sources of PAHs were associated with a $30-50 \%$ increase in breast cancer risk (28). Similarly, PAH profiles from inhalation and digestion could be modifiable risk factors (28). Further studies are warranted to monitor the multiple sources of $\mathrm{PAH}$ emissions between coal and wood combustion for cooking and elucidate their association with breast cancer.

The chief strengths of this study include the large number of cooking fuel users (in particular for coal users), geographical diversity and completeness of data collection. Moreover, to discount the exposure that is thought irrelevant to the outcome, we conducted sensitivity analyses and selected 5-year or 10-year lag period. Our study has several limitations as well. First, the cross-sectional design of this study precludes a causal inference between solid fuel exposure and risk of breast cancer. Further prospective studies are needed to confirm the causal relationship. Second, like other CKB studies, recall-bias is possible because of the self-reported nature of the baseline survey. Nevertheless, about $78 \%$ of the participants in the resurvey reported the same type of cooking fuel as in the baseline survey, and the kappa value for cooking information was acceptable (0.6) (42). The physician-diagnosed cancer history was also confirmed by hospital admission information in the resurvey. Third, although self-reported primary cooking fuel has been adopted as a practical proxy of HAP in many studies, it remains an inherently limited indicator (3). It is possible that secondary fuel exposure and pollutants from neighborhood also contribute to the HAP. Primary fuel use represents a compromise which balances imperative of capturing detailed information on HAP with the pragmatic considerations such as feasibility of conducting surveys and eliciting reliable information from participants. Fourth, we did not account for ambient air pollution that might contribute to breast cancer risk. Since CKB public database did not disclose home address due to privacy protection, GIS method (grid-based method) cannot be used to locate and control for ambient air pollutants. However, CKB disclosed the province where study participants were resided in, and in each province the study participants were all located in the same community or village. Although we could not obtain ambient air pollution data, we adjusted for study region in all models and assumed a similar pattern of ambient air pollution exposure from the same region (29). We expected this strategy could somehow account for residual confounding from ambient air pollution (29). Finally, CKB project does not include histotype or genetic information.

\section{CONCLUSION}

Household air pollution from solid cooking fuel combustion may elevate the risk of female breast cancer. The strength of the association is higher in long-term coal users than in longterm wood users. This study may have global implications as many countries are in the transition to clean energy. Efforts to disseminate clean and affordable alternatives (electricity and gas) are gaining momentum in LMICs (3). Adoption of sustainable clean energy solutions hinges on improved understanding of gender dynamics of household energy use and sex-specific health impacts (3). Gender-responsive interventions which taking into account the gender roles in household energy acquisition and uses are required. More evidence on health impacts on females is needed for implementation of policies to promote health, as females are often the primary cooking fuel users and the ones who benefit most from transition to clean cooking fuels (3).

\section{DATA AVAILABILITY STATEMENT}

The raw data supporting the conclusions of this article will be made available by the authors, without undue reservation. 


\section{ETHICS STATEMENT}

The studies involving human participants were reviewed and approved by Ethical Review Committee of the Chinese Center for Disease Control and Prevention and the Oxford Tropical Research Ethics Committee. The patients/participants provided their written informed consent to participate in this study.

\section{AUTHOR CONTRIBUTIONS}

TL and SW designed the study. SW acquired the data. TL analyzed and drafted the manuscript. All authors contributed to the interpretation of data and revised the article. All authors read and approved the final article.

\section{FUNDING}

The CKB baseline survey and first resurvey was supported by grants (2016YFC0900500, 2016YFC0900501, and 2016YFC0900504) from the National Key Research and Development Program of China, grants from the Kadoorie Charitable Foundation in Hong Kong and grants (088158/Z/09/Z, 104085/Z/14/Z, and 104085/Z/14/Z) from Wellcome Trust in the UK. The funders had no role in the

\section{REFERENCES}

1. WHO. Household air pollution and health. (2018) Available from: https:// www.who.int/news-room/fact-sheets/detail/household-air-pollutionand-health\#:\$ $\backslash$ sim\$:text=3.8\%20million\%20people\%20a\%20year\%20die \%20prematurely\%20from, 27\%\%20are\%20due\%20to\%20pneumonia\%2018\% $\% 20$ from\%20stroke (accessed January 23 2021).

2. WHO. Household air pollution - the world's leading environmental health risk. (2020) Available from: http://www.who.int/airpollution/household/about/en/ (accessed March 12 2020).

3. WHO. Burning Opportunity: Clean Household Energy for Health, Sustainable Development, and Wellbeing of Women and Children. Geneva: WHO Press (2016). Available online at: www.who.int/airpollution/publications/burning opportunities/en/ (accessed January 16, 2020).

4. WHO, WHO indoor air quality guidelines: household fuel combustion. Geneva: WHO Document Production Services (2014)

5. Gullett BK, Touati A, Hays MD. PCDD/F, PCB, $\mathrm{HxCBz}, \mathrm{PAH}$, and PM emission factors for fireplace and woodstove combustion in the San Francisco Bay region. Environ Sci Technol. (2003). 37:1758-65. doi: 10.1021/es026373c

6. McDonald JD, Zielinska B, Fujita EM, Sagebiel JC, Chow JC, Watson JC. Fine particle and gaseous emission rates from residential wood combustion. Environ Sci Technol. (2000). 34:2080-2091. doi: 10.1021/es9909632

7. Raspanti GA, Hashibe M, Siwakoti B, Wei M, Thakur BK, Pun CB, et al., Household air pollution and lung cancer risk among never-smokers in Nepal. Environ Res. (2016) 147:141-5. doi: 10.1016/j.envres.2016.02.008

8. RoggeWF, Hildemann LM, Mazurek MA, Cass GR, Simoneit BRT. Sources of fine organic aerosol. 9. Pine, oak and synthetic log combustion in residential fireplaces. Environ Sci Technol. (1998) 32:13-22. doi: 10.1021/es960930b

9. Zhang JJ, Smith KR. Household air pollution from coal and biomass fuels in China: Measurements, health impacts, and interventions. Environ Health Perspect. (2007). 115:848-55. doi: 10.1289/ehp.9479

10. IEA. World energy outlook: 2017. Paris: International Energy Agency. (2017)

11. IARC. Household use of solid fuels and high-temperature frying. IARC Monogr Eval Carcinog Risks Hum. (2010) 95:1-430.

12. Callahan CL, Bonner MR, Nie J, Han D, Wang Y, Tao MH, et al., Lifetime exposure to ambient air pollution and methylation of tumor study design, data collection, data analysis and interpretation, writing of the report or decision to submit the article for publication. The present study was supported by the National Natural Science Foundation (Grant No. 81502884) and the National Key Research and Development Program of China [2018YFC1311704].

\section{ACKNOWLEDGMENTS}

We thank Chinese Center for Disease Control and Prevention, Chinese Ministry of Health, National Health and Family Planning Commission of China, and 10 provincial/regional Health Administrative Departments. The most important acknowledgment is to the participants in the study and the members of the survey teams in each of the 10 regional centers, as well as to the project development and management teams based at Beijing, Oxford and the 10 regional centers.

\section{SUPPLEMENTARY MATERIAL}

The Supplementary Material for this article can be found online at: https://www.frontiersin.org/articles/10.3389/fpubh. 2021.677851/full\#supplementary-material

suppressor genes in breast tumors. Environm Res, (2018) 161:41824. doi: 10.1016/j.envres.2017.11.040

13. Andersen ZJ, Stafoggia M, Weinmayr G, Pedersen M, Galassi C, Jorgensen JT, et al., Long-term exposure to ambient air pollution and incidence of postmenopausal breast cancer in 15 European cohorts within the ESCAPE project. Environ Health Perspect. (2017) 125:107005. doi: 10.1289/isee.2016.3966

14. Raaschou-Nielsen O, Andersen ZJ, Hvidberg M, Jensen SS, Ketzel M, Sorensen M, et al., Air pollution from traffic and cancer incidence: a Danish cohort study. Environm Health. (2011) 10:11. doi: 10.1186/1476-069X-10-67

15. White AJ, Sandler DP. Indoor wood-burning stove and fireplace use and breast cancer in a prospective cohort study. Environ Health Perspect. (2017) 125:077011. doi: 10.1289/EHP827

16. White AJ, Teitelbaum SL, Stellman SD, Beyea J, Steck SE, Mordukhovich I, et al., Indoor air pollution exposure from use of indoor stoves and fireplaces in association with breast cancer: a case-control study. Environ Health. (2014) 13:108. doi: 10.1186/1476-069X-13-108

17. Liu T, Song Y, Chen R, Zheng R, Wang S, Li L. Solid fuel use for heating and risks of breast and cervical cancer mortality in China. Environm Res. (2020) 186: 109578. doi: 10.1016/j.envres.2020.109578

18. Li J, Qin C, Lv J, Guo Y, Bian Z, Zhou W, et al., Solid fuel use and incident COPD in chinese adults: findings from the china kadoorie biobank. Environ Health Perspect. (2019) 127:57008. doi: 10.1289/EHP2856

19. Chen Y, Shen G, Liu W, Du W, Su S, Duan Y, et al. Field measurement and estimate of gaseous and particle pollutant emissions from cooking and space heating processes in rural households, northern China. Atmos Environm. (2016). 125:265-71. doi: 10.1016/j.atmosenv.2015.11.032

20. Lissowska J, Bardin-Mikolajczak A, Fletcher T, Zaridze D, SzeszeniaDabrowska N, Rudnai $\mathrm{P}$, et al., Lung cancer and indoor pollution from heating and cooking with solid fuels: the IARC international multicentre case-control study in Eastern/Central Europe and the United Kingdom. Am J Epidemiol. (2005) 162:326-33. doi: 10.1093/aje/k wi204

21. Chen Z, Lee L, Chen J, Collins R, Wu F, Guo Y, et al., Cohort profile: the Kadoorie Study of Chronic Disease in China (KSCDC). Int J Epidemiol, (2005) 34:1243-9. doi: 10.1093/ije/dyi174 
22. Chen Z, Chen J, Collins R, Guo Y, Peto R, Wu F, et al., China Kadoorie Biobank of 0.5 million people: survey methods, baseline characteristics and long-term follow-up. Int J Epidemiol. (2011) 40:1652-66. doi: 10.1093/ije/d yr120

23. Chan KH, Kurmi OP, Bennett DA, Yang L, Chen Y, Tan Y, et al., Solid Fuel Use and Risks of Respiratory Diseases A Cohort Study of 280,000 Chinese Never-Smokers. Am J Respir Crit Care Med. (2019). 199:352-361. doi: 10.1164/rccm.201803-0432OC

24. Chan KH, Bennett DA, Lam KBH, Kurmi OP, Chen Z, G. China Kadoorie Biobank Study, Risk of cardiovascular death by long-term solid fuel use for cooking and implications of switching to clean fuels: a prospective cohort study of 340,000 chinese adults. Eur Heart J. (2018). 39:498. doi: 10.1093/eurheartj/ehy565.P2544

25. Chan KH, Bennett DA, Kurmi OP, Yang L, Chen Y, Lv J, et al., Solid fuels for cooking and tobacco use and risk of major chronic liver disease mortality: a prospective cohort study of 0.5 million Chinese adults. Int J Epidemiol. (2020) 49:45-55. doi: 10.1093/ije/dyz216

26. White AJ, Sandler DP, D'Aloisio AA, Stanczyk F, Whitworth KW, Baird $\mathrm{DD}$, et al., Antimullerian hormone in relation to tobacco and marijuana use and sources of indoor heating/cooking. Fertil Steril. (2016) 106:72330. doi: 10.1016/j.fertnstert.2016.05.015

27. Li XY, Yu CQ, Guo Y, Bian Z, Shen ZW, Yang L, et al., Association between tea consumption and risk of cancer: a prospective cohort study of 0.5 million Chinese adults. European Journal of Epidemiology. (2019) 34:75363. doi: 10.1007/s10654-019-00530-5

28. White AJ, Bradshaw PT, Herring AH, Teitelbaum SL, Beyea J, Stellman $\mathrm{SD}$, et al., Exposure to multiple sources of polycyclic aromatic hydrocarbons and breast cancer incidence. Environm Int. (2016) 89-90:185-192. doi: 10.1016/j.envint.2016.02.009

29. YuK, Lv J, Qiu G, Yu C, Guo Y, Bian Z, et al., Cooking fuels and risk of allcause and cardiopulmonary mortality in urban China: a prospective cohort study. Lancet Global Health. (2020) 8:E430-9.

30. IARC. Some non-heterocyclic polycyclic aromatic hydrocarbons and some related exposures. IARC Monogr. Eval Carcinog Risks Hum. (2010) 92: 765-71. doi: 10.1016/S2214-109X(19)30525-X

31. Shen H, Huang Y, Wang R, Zhu D, Li W, Shen G, et al., Global atmospheric emissions of polycyclic aromatic hydrocarbons from 1960 to 2008 and future predictions. Environ Sci Technol. (2013) 47:6415-24. doi: 10.1021/es40 $0857 \mathrm{z}$

32. $\mathrm{Xu} \mathrm{S}$, Liu $\mathrm{W}$, Tao S, Emission of polycyclic aromatic hydrocarbons in China. Environ Sci Technol, (2006). 40:702-8. doi: 10.1021/es051 7062

33. Du W, Wang J, Zhuo S, Zhong Q, Wang W, Chen Y, et al. Emissions of particulate PAHs from solid fuel combustion in indoor cookstoves. Sci Total Environ. (2021) 771:145411. doi: 10.1016/j.scitotenv.2021. 145411
34. Balmes JR. Household air pollution from domestic combustion of solid fuels and health. J Allergy Clin Immunol. (2019) 143:1979-88. doi: 10.1016/j.jaci.2019.04.017

35. Mancini R, Romano G, Sgambato A, Flamini G, Giovagnoli MR, Boninsegna A, et al. Polycyclic aromatic hydrocarbon-DNA adducts in cervical smears of smokers and nonsmokers. Gynecologic Oncology. (1999) 75:6871. doi: 10.1006/gyno.1999.5525

36. Rorke EA, Sizemore N, Mukhtar H, Couch LH, Howard PC. Polycyclic aromatic hydrocarbons enhance terminal cell death of human ectocervical cells. Int J Oncology. (1998) 13:557-63. doi: 10.3892/ijo.13.3.557

37. Miller E. Some current perspectives on chemical carcinogenesis in humans and experimental animals: presidential address. Cancer Res. (1978) 38:14791496.

38. Gammon MD, Sagiv SK, Eng SM, Shantakumar S, Gaudet MM, Teitelbaum SL, et al., Polycyclic aromatic hydrocarbon-DNA adducts and breast cancer: a pooled analysis. Arch Environ Health. (2004) 59:640-9. doi: 10.1080/00039890409602948

39. Pfeifer GP, Denissenko MF, Olivier M, Tretyakova N, Hecht SS, Hainaut P. Tobacco smoke carcinogens, DNA damage and p53 mutations in smokingassociated cancers. Oncogene. (2002). 21:7435-51. doi: 10.1038/sj.onc.1205803

40. Delgado-Saborit JM, Stark C, Harrison RM. Carcinogenic potential, levels and sources of polycyclic aromatic hydrocarbon mixtures in indoor and outdoor environments and their implications for air quality standards. Environ Int. (2011). 37:383--92. doi: 10.1016/j.envint.2010.10.011

41. Shen G, Chen Y, Xue C, Lin N, Huang Y, Shen H, et al. Pollutant emissions from improved coal- and wood-fuelled cookstoves in rural households. Environ Sci Technol. (2015). 49:6590-8. doi: 10.1021/es506343z

42. Yu K, Qiu G, Chan KH, Lam KH, Kurmi OP, Bennett DA, et al., Association of solid fuel use with risk of cardiovascular and all-cause mortality in rural China. JAMA. (2018) 319:1351-61. doi: 10.1001/jama.2018.2151

Conflict of Interest: The authors declare that the research was conducted in the absence of any commercial or financial relationships that could be construed as a potential conflict of interest.

Publisher's Note: All claims expressed in this article are solely those of the authors and do not necessarily represent those of their affiliated organizations, or those of the publisher, the editors and the reviewers. Any product that may be evaluated in this article, or claim that may be made by its manufacturer, is not guaranteed or endorsed by the publisher.

Copyright (C) 2021 Liu, Chen, Zheng, Li and Wang. This is an open-access article distributed under the terms of the Creative Commons Attribution License (CC BY). The use, distribution or reproduction in other forums is permitted, provided the original author(s) and the copyright owner(s) are credited and that the original publication in this journal is cited, in accordance with accepted academic practice. No use, distribution or reproduction is permitted which does not comply with these terms. 